\title{
Tagging of Age 1 Herring (Clupea harengus L.) and Their Movement Along the Maine and New Brunswick Coasts
}

\author{
Edwin P. Creaser and David A. Libby \\ Maine Department of Marine Resources, Fishery Research Laboratory \\ West Boothbay Harbor, Maine, USA 04575
}

\begin{abstract}
A method was developed for tagging age 1 herring, and tag recovery results were analyzed for movement patterns. Use of new transport and holding techniques to avoid handling the fish prior to tagging and the use of small yellow, fine fabric, T-bar spaghetti tags (Floy) are considered to be the primary reasons for long-term ( $>1$ year) survival of a significant proportion of tagged fish. A total of 16,084 age 1 herring were tagged and released in 1982 and 1983. The overall total recovery rate from 5 taggings was $7.57 \%$ (range $0.21-19.58 \%$ ). The overall effective recovery rate (i.e. from the 15 th day after release) was $1.01 \%$ (range $0.21-1.76 \%$ ). The results strongly suggest that age 1 herring, observed (and tagged) in the western and central waters of Maine during the 3 rd and 4 th calendar quarters, contribute to the commercial catch of age 2 fish east of the area where they were tagged during the 2 nd and $3 r d$ quarters of the following year. Age 1 herring, observed (and tagged) in easternmost Maine and western New Brunswick waters during the 3 rd and 4 th quarters, remain in the same area where they contribute to the commercial fishery for age 2 fish during the 2 nd and 3 rd quarters of the following year.
\end{abstract}

\section{Introduction}

Several methods have been employed in marking small fish for short term studies on movement. McKenzie and Skud (1958) and McKenzie and Tibbo (1961) marked $1-3$ year old herring, measuring 14.2 to $18.7 \mathrm{~cm}$ and 9.9 to $20.0 \mathrm{~cm}$ respectively, with tags attached to the operculum. They found that the operculum tag was only useful for short-term studies of movement. The mean time before recapture was 12 days, the longest time was 165 days and the greatest straight-line distance traveled was 55 naut. miles $(102 \mathrm{~km})$. Their results indicate that herring move in and out of Passamaquoddy Bay irregularly throughout the summer and autumn and that there was little interchange of herring between the Passamaquoddy region and the coasts of Maine and Nova Scotia. Watson (1961), using a technique similar to that of Johnson and Fields (1959), branded immature herring of $12.5-15.5 \mathrm{~cm}$ in length. Although the brands were still visible after 7 months, they "would hardly have been noticed by a casual observer". In a later study, Watson (1963) developed a polyvinyl chloride spaghetti tag which was looped through the dorsal musculature of the herring near the anterior end of the dorsal fin. The mean time before recapture of herring tagged by this method was 18 days, the longest time was 391 days, and the greatest straight-line distance traveled was 50 naut. miles ( 81 $\mathrm{km}$ ). Although this tagging method was suitable for herring in excess of 4 inches $(10.2 \mathrm{~cm})$, it was very time consuming and a three-man team was only able to tag at the rate of 100 fish per hour under average conditions.
The objectives of the present study were to (a) assess a rapid method for tagging age 1 herring which would yield recoveries for at least 1 year after release and (b) determine whether age 1 herring, observed and tagged in one region along the Maine and New Brunswick coasts during the autumn, contributed to the commercial fishery for age 2 fish in the same regions or other regions during the following spring and summer.

\section{Materials and Methods}

It was evident from preliminary attempts at catching, handling and transporting small herring, as well as from observations reported by Watson (1963), that they are extremely fragile and that the tagging mortality rate is related to the extent of handling. Thus, a method was developed to minimize handling and confinement time of fish prior to tagging.

Age 1 herring of desirable size $(>100 \mathrm{~mm})$ were located through communications with stop-seine and weir fishermen. Fish were seined from stop seine pockets and weirs and coaxed to swim into cubical holding pockets with $1.8 \mathrm{~m}$ sides. When a suitable quantity of fish was obtained, the pockets were towed away from the commercial fishing site. A wooden towing bar was fastened to the forward edge of each holding pocket and weights were strategically attached to the bar to prevent the pockets from collapsing during towing. Pockets were towed well behind the turbulence caused by the 4-m Boston Whaler's propeller. 
Shallow floating trays were used within the holding pockets to concentrate the fish and expedite their capture. Each tray consisted of a wooden frame $(76 \mathrm{~cm}$ long, $38 \mathrm{~cm}$ wide and $8 \mathrm{~cm}$ deep) with nylon netting ( 3 $\mathrm{mm}$ mesh) attached loosely to the bottom. Individual herring were removed from a tray and positioned so that the head was held in the palm and the posterior dorsal portion was exposed between the thumb and index finger of one hand. The tag was applied with an applicator held in the other hand. This was the only time during the entire capture, transfer and tagging procedure when fish were removed from the water. Each tagger was responsible for catching, holding and tagging his own fish.

Age 1 herring were tagged with yellow, Floy, fine fabric, T-bar spaghetti tags using cartridge-fed Dennison fine fabric tagging guns (Dennison Mfg. Co., Framingham, Mass., USA) equipped with fine fabric needles $(1.3 \mathrm{~mm}$ outside diameter). These tags are substantially smaller than the Floy FD-67 and FD-68B tags which have been commonly used in Canadian and U.S. juvenile and adult herring tagging studies (Fig. 1). Tags were inserted diagonally through the anterior dorsal musculature between the internural bones at the base of the dorsal fin. The needles were directed in an anterior direction to avoid perforating the fish with the T-bar.

The area from Cape Cod to eastern Nova Scotia has been divided into regions I-XIV to facilitate the analysis of tag release and recovery data (Stobo, 1983). Age 1 herring were tagged in regions $\mathrm{V}, \mathrm{VI}, \mathrm{VII}$, and $\mathrm{X}$ (Fig. 2). The tagging program was widely publicized and a reward of $\$ 3$ (U.S.) was paid for each tag recovery. Only recoveries with complete information (tag number, date, and location of capture) were considered in this paper.

A 50-fish sample was collected during each tagging experiment. Length was recorded in $\mathrm{mm}$ from the tip of the snout to the longest lobe of the caudal fin. Except for the St. Croix sample (15 fish), age was determined from otoliths extracted from 30 fish.

Herring usually spawn between August and October along the Maine coast. Fish that were tagged during the calendar year (Jan-Dec) immediately following that in which they were spawned were designated as age 1 .

The numbers of tag recoveries are presented as "total" recoveries (from the day of release) and "effective" recoveries (from the 15 th day after release). Recaptures during the first 14 days were not considered "effective" recoveries for the reasons that were discussed by Creaser et al. (1984).

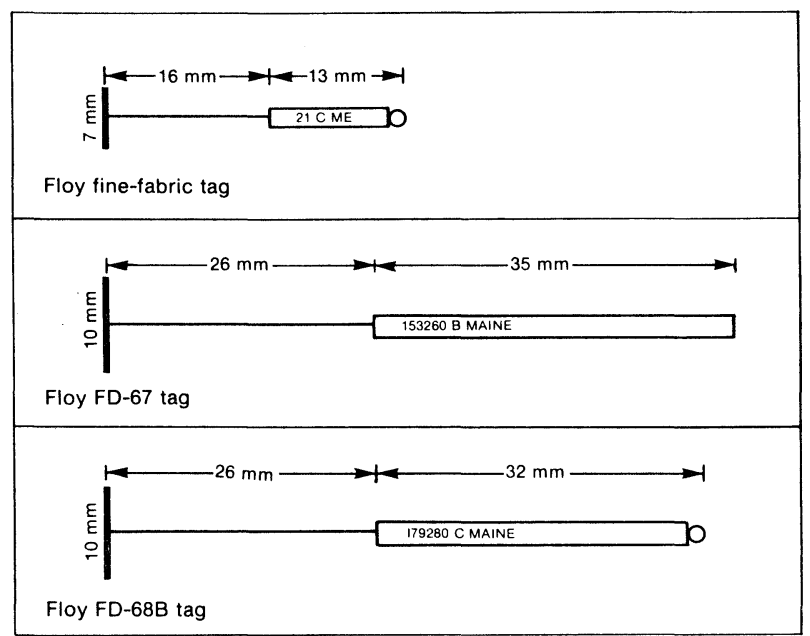

Fig. 1. Comparison of the Floy fine-fabric tag with the Floy FD-67 and FD-68B tags.

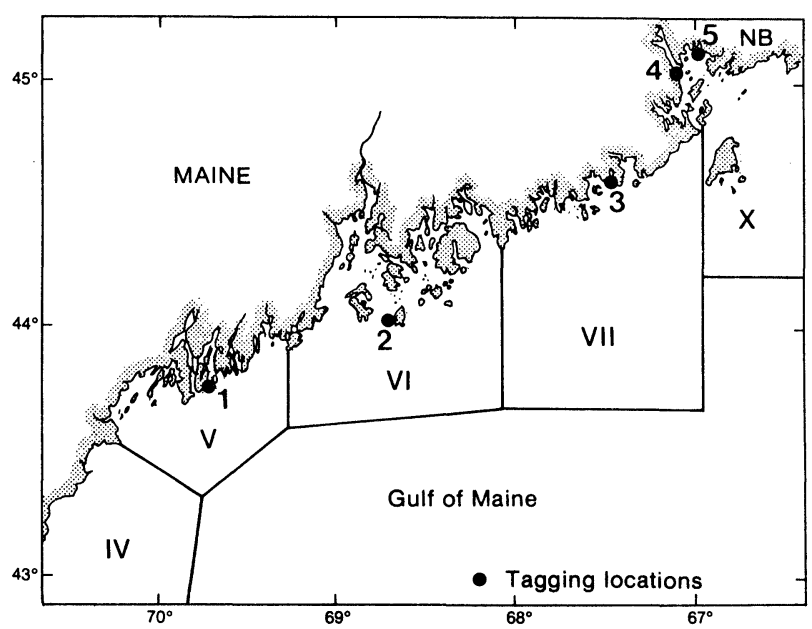

Fig. 2. Regions established for analysis of data on herring tag recoveries off Maine and New Brunswick (roman numerals) and tagging locations (arabic numerals).

\section{Results and Discussion}

Historically, the herring fishery along the Maine and New Brunswick coasts is based on juvenile fish caught in fixed gear (stop-seines and weirs). Although some age 1 herring are harvested during the 4th calendar quarter of a given year, the majority are usually harvested at age 2 during the late 2 nd and 3 rd quarters of the following year.

\section{Tagging results}

A total of 16,084 age 1 herring were tagged in four regions $(\mathrm{V}, \mathrm{VI}, \mathrm{VII}$, and $\mathrm{X}$ ) during late summer-early autumn of 1982 and 1983 in five tagging operations (Table 1). Mean lengths were between 10.1 and $14.9 \mathrm{~cm}$ 
TABLE 1. Summary of tag release and recovery data from five taggings of age 1 herring in $1982-83$. (Herring were obtained by stop-seine for taggings 1 and 5 and by weir for the remainder.)

\begin{tabular}{|c|c|c|c|c|c|c|c|c|c|c|}
\hline \multirow{2}{*}{$\begin{array}{c}\text { Tagging locations } \\
\text { (see Fig. 1) }\end{array}$} & \multirow{2}{*}{$\begin{array}{l}\text { Tagging } \\
\text { region }\end{array}$} & \multirow{2}{*}{$\begin{array}{l}\text { Tagging } \\
\text { date }\end{array}$} & \multirow{2}{*}{$\begin{array}{c}\text { Mean } \\
\text { length } \\
(\mathrm{mm})\end{array}$} & \multirow{2}{*}{$\begin{array}{c}\text { No. of } \\
\text { tagged } \\
\text { fish }\end{array}$} & \multicolumn{2}{|c|}{$\begin{array}{c}\text { Total } \\
\text { recoveries }\end{array}$} & \multicolumn{2}{|c|}{$\begin{array}{l}\text { Effective } \\
\text { recoveries }^{a} \\
\end{array}$} & \multirow{2}{*}{$\begin{array}{c}\text { Recovered } \\
\text { after } \\
1 \text { year }\end{array}$} & \multirow{2}{*}{$\begin{array}{c}\text { Tagging } \\
\text { rate }^{\mathrm{b}}\end{array}$} \\
\hline & & & & & No. & $\%$ & No. & $\%$ & & \\
\hline 1. Christmas Cove & V & 24 Oct 1983 & 149 & 2,958 & 152 & $(5.14)$ & 39 & $(1.32)$ & 3 & 573 \\
\hline 2. Isle au Haut & VI & 30 Sep 1983 & 129 & 4,965 & 22 & $(0.44)$ & 22 & $(0.44)$ & 7 & 552 \\
\hline 3. Little Kennebec & VII & 25 Aug 1983 & 108 & 1,000 & 4 & $(0.40)$ & 4 & $(0.40)$ & 4 & 240 \\
\hline 4. St. Croix River & $\mathrm{X}$ & 01 Sep 1982 & 101 & 1,875 & 4 & $(0.21)$ & 4 & $(0.21)$ & 1 & 288 \\
\hline \multirow[t]{2}{*}{ 5. Bocabec Cove } & $x$ & 23 Sep 1983 & 130 & 5,286 & 1,035 & $(19.58)$ & 93 & $(1.76)$ & 11 & 470 \\
\hline & & & & 16,084 & 1,217 & $(7.57)$ & 162 & $(1.01)$ & 26 & 425 \\
\hline
\end{tabular}

${ }^{a}$ Excludes recoveries during first 14 days after the tagging date.

b Number tagged per man-hour.

(with standard error about 0.1 for each sample). Overall total and effective recovery rates were 7.57 and $1.01 \%$ respectively. Of 162 effective recoveries, 26 $(16 \%)$ occurred more than 1 year after tagging. Maximum time at large was 728 days. The overall total recovery rate reflects a high return rate of $19.6 \%$ from region $X$ (Bocabec Cove) where an intense weir fishery existed immediately after tagging. The overall effective recovery rate is less than the effective rates for older fish of 1.1-7.3\% for Bay of Fundy experiments (Stobo, MS 1976), 1.4-1.6\% for Southwest Nova Scotia and $3.7-4.3 \%$ for Sydney Bight (Stobo, MS 1982), and 4.2-4.6\% for the Maine coast (Creaser et al., 1984). The results suggest that tagging mortality or tag loss, or both, are higher for herring tagged at age 1 compared to older fish. Sufficient recoveries were obtained, however, to warrant the continued use of the Floy fine fabric tag in future tagging experiments.

\section{Handling and tagging methods}

Survival time of tagged age 1 herring in this study appears to have been longer than that in earlier studies, a substantial proportion of effective recoveries occurring after 1 year at large. This probably resulted in large part from attempts to reduce scale loss at all stages of handling and tagging the fish. The inverse relationship between scale loss and tag recovery rate (due to decreased mortality) is well known (Jensen, 1955). Past practices of transferring fish from seine to pocket using a dipnet, using holding pockets which partially collapsed during towing, and towing the pockets too close to the boat, all resulted in increased scale loss and were therefore not desirable in handling fragile age 1 herring. The use of shallow tagging trays to insure rapid capture of individual fish, and the subduing effects of holding the fish with the head enclosed within the palm of the hand, increased tagging speed over that in earlier experiments, thus minimizing scale loss by minimizing confinement time. The mean tagging rate was $425 \mathrm{fish} / \mathrm{man}$-hour with a range of 240-573 (Table 1). The suitability of the Floy fine fabric tag for herring of this size no doubt also contributed to the first objective of this study being satisfactorily met.

\section{Movement patterns}

Effective tag recoveries from each tagging are shown by region and calendar quarter in Table 2 . Most age 1 herring tagged in regions $V, V I$ and $X$ remained in the tagging region during the first quarter at age 2. An exception to this was noted in the region $\mathrm{VI}$ tagging where two individuals were recovered in region $V$ (Bantam Ledge off Boothbay Harbor, Maine). It is unknown whether age 1 herring tagged in region VII remained in that region during the first quarter at age 2 , because no recoveries were reported until the 3rd quarter at age 2. Fish tagged at age 1 in regions $V$ and $V I$ were invariably recaptured east of their tagging sites during the summer (3rd quarter) and fall (4th quarter) at age 2. An eastward movement has also been recorded for juvenile herring tagged at age 2 in regions $V$ and $\mathrm{VI}$ (Creaser et al., 1984). All recoveries from age 1 herring tagged in region $X$ were from region $X$. Similar results were reported for herring tagged at age 2 in region $X$ (Creaser et al., 1984). The results show that age 1 herring, observed in regions $\mathrm{V}$ and $\mathrm{VI}$ during the 3rd and 4th quarters, contribute to the commercial catch in a region east of the one in which they were tagged. However, the results of the two taggings of age 1 herring in region $X$ showed that these fish contribute to the commercial fishery for age 2 herring in region $X$ during the 2nd and 3rd quarters of the following year. No conclusions regarding the movement of age 1 herring tagged in region VII can be drawn because no tag returns were reported during the first 4 quarters at large and only four recoveries were reported thereafter. The nearly total lack of tag recoveries from all regions during the 2 nd quarter is consistent with expected recoveries from a fishery which begins late in the 2nd quarter.

\section{Acknowledgements}

We gratefully acknowledge the cooperation of the U.S. National Marine Fisheries Service (NMFS) and the New England Fishery Management Council who provided financial assistance. We are indebted to Maine 
TABLE 2. Distribution of tag recoveries by region and calendar quarter for age 1 herring tagged in regions V, VI, VII and X in 1982 and 1983. (Shaded areas represent interpreted migration patterns.)

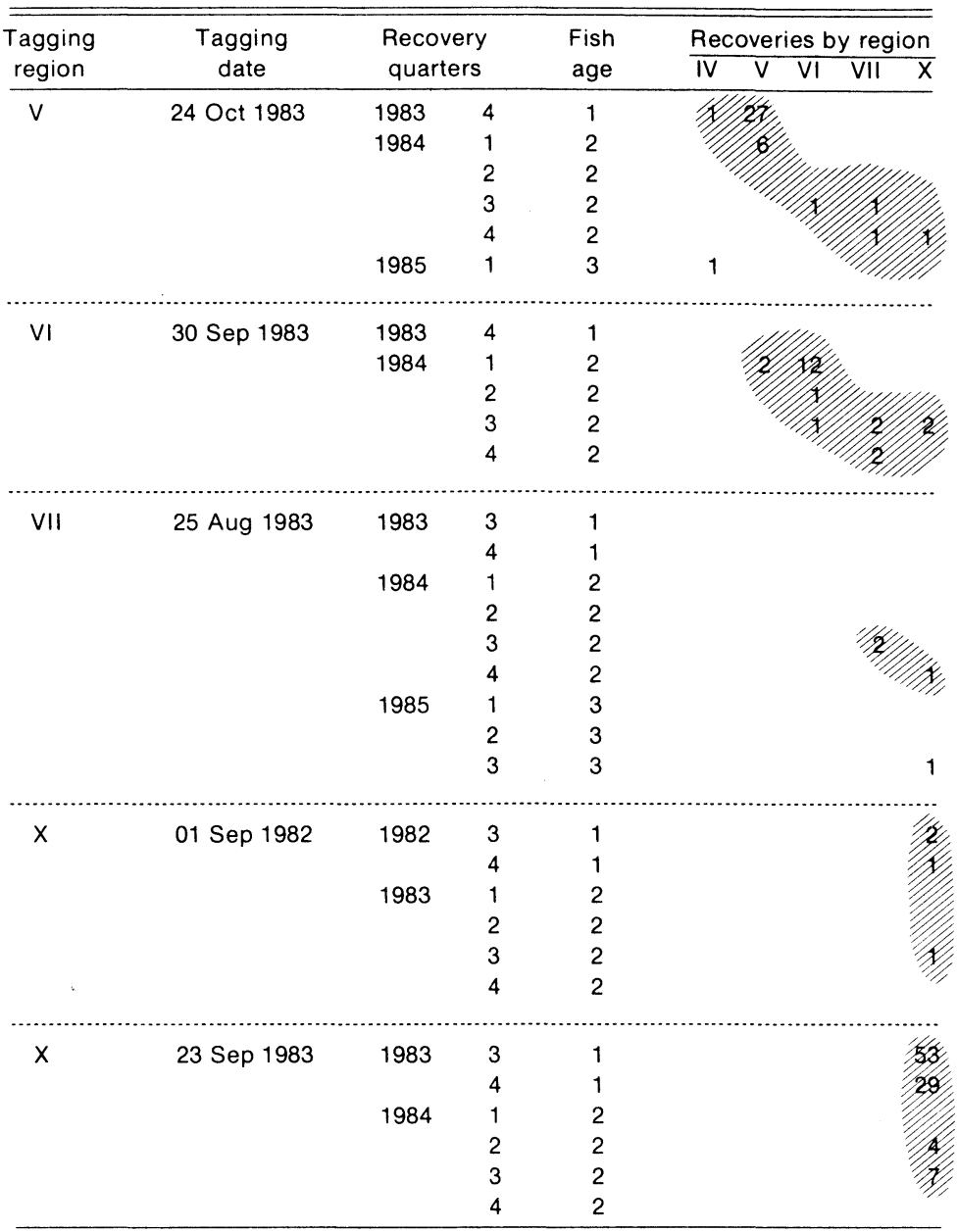

and New Brunswick fishermen who supplied us with fish and to Canadian Department of Fisheries and Oceans personnel who assisted with the tagging in Bocabec Cove, New Brunswick. Appreciation is extended to personnel in herring processing plants and NMFS port samplers who retrieved and accumulated tags, recorded tag numbers, recovery dates and locations, and mailed the information to us. Special appreciation is also extended to Margaret Hunter for computer programming services, Jean Chenoweth for age analysis, James Rollins for drafting and photographic services, and Pamela Mancuso for typing the manuscript.

\section{References}

CREASER, E. P., D. A. LIBBY, and G. D. SPEIRS. 1984. Seasonal movements of juvenile and adult herring. Clupea harengus L., tagged along the Maine coast. J. Northw. Atl. Fish. Sci., 5: 71-78.
JENSEN, A. J. C. 1955. Danish herring tagging inside the Scaw, 1945-1952. ICES Rapp. Proc.-Verb., 140: 30-32.

JOHNSON, D. E., and P. F. FIELDS. 1959. The effectiveness of an electric hot-wire branding technique for marking steelhead fingerling trout. Tech. Rep., College of Fish., Univ. of Washington, Seattle, Wash., No. 47, 4 p.

MCKENZIE, R. A., and B. E. SKUD. 1958. Herring migrations in the Passamaquoddy region. J. Fish. Res. Board Can., 15 1329-1343.

MCKENZIE, R. A., and S. N. TIBBO. 1961. Herring movements in the Bay of Fundy and Gulf of Maine, 1957 and 1958. J. Fish. Res. Board Can., 18: 221-252.

STOBO, W. T. MS 1976. Movements of herring tagged in the Bay of Fundy - update. ICNAF Res. Doc., No. 48, Serial No. $3834,16 \mathrm{p}$.

MS 1982. Tagging studies on Scotian Shelf herring NAFO SCR Doc., No. 108, Serial No. N617, 16 p.

1983. Report of ad hoc working group on herring tagging. NAFO Sci. Coun. Rep., 1983: 77-101.

WATSON, J. E. 1961. The branding of sea herring as a shortterm mark. Prog. Fish. Cult., 23: 105.

1963. A method of tagging immature herring. Spec. Sci. Rep. US Fish. Wildl. Serv. - Fish., 451, 7 p. 